\title{
MAPPING LITHOLOGICAL AND MINERALOGICAL UNITS USING HYPERSPECTRAL IMAGERY
}

\author{
Rayan Ghazi Thannoun ${ }^{1 a^{*}}$
}

\author{
${ }^{a}$ Remote Sensing Center, Mosul University, IRAQ. Email: rayan.ghazi@uomosul.edu.iq ${ }^{1}$ \\ Corresponding author: rayan.ghazi@uomosul.edu.iq \\ Received: $10^{\text {th }}$ April $2020 \quad$ Accepted: $19^{\text {th }}$ Aug 2020 \\ Published: $28^{\text {th }}$ Feb 2021 \\ DOI: https://doi.org/10.22452/mjs.vol40no1.8
}

\begin{abstract}
Hyperspectral images such as the Earth Observer-1 (EO-1) provides an efficient method of mapping surface mineralogy because it can measures the energy in narrower bands compared with multispectral sensors. Kirkuk anticline which located in northern Iraq is one of the most petroleum-rich provinces. It is an asymmetrical, cylindrical anticline, with a fold axis trends towards North West- East, South East. Tectonically, Kirkuk anticline is located in the Low Folded Zone of the Foreland Fold Belt which belongs to the Zagros Collision Zone. The primary goal of the study is to apply satellite processing and techniques on the Eo-1 imagery to identify lithological and mineral units at part of Kirkuk anticline in northern Iraq. At the beginning of atmospheric influence, the EO-1 image was corrected using the FLAASH module in ENVI software. Processing of Minimum Noise Fraction (MNF) transformation was applied and then data dimensionality was reduced, as well as, the processing of pixel purity index (PPI) was extended to spatial reduction. This study tested the potential of spectral angle mapper supervised classification (SAM) classification for mapping the lithological and mineral units using the Hyperion imagery. Three different sources of endmembers or spectra were used for SAM classifications. Source one: is done by Analytical Spectral Devices (ASD) field Spectrometer in spectral analysis laboratory (Remote Sensing Center- Mosul University). Source two: reference spectra have been taken from the USGS spectral library. Source three: extracting endmembers from the purest pixels in the Hyperion image, which was done by applying (Minimum noise fraction) and (pixel purity index). The endmembers were provided and generated as the training area for SAM classification. The present findings indicate the great potential of EO-1 data for mapping the distribution of alteration minerals and lithological units in part of Kirkuk anticline. The classified Hyperion image shows that Jarosite and Illite are the most dominant altered minerals. In addition, the main lithological units of the upper member of Fatha formation are exposed in the central core of Kirkuk anticline with small outcrops scattered towards the flanks. It has been observed that the location of the main lithological unit is in full conformity with the geological map.
\end{abstract}

Keywords: Spectral angle mapper, EO-1 imagery, hyperspectral, mineralogical and lithological unit, (ASD) field spectrometer 


\section{INTRODUCTION}

Recently, Remote sensing data become significant instruments that have been used in many practical researches related to natural resources and mineral mapping (Melesse et al., 2007; Saibi et al., 2018). Geologists are currently working in companies of mineral exploration, using several data to search for new mineral deposits (jaber Nasir, 2018). Traditional remote sensing products, as in the Landsat $\mathrm{ETM}^{+}$and Landsat multispectral scanner, are often limited in spectral and spatial resolution and are produced by sensors that measure electromagnetic energy within several spectral bands between 3 to 10 bands. In this context, multispectral images have border spectral bands, therefore they are not able to extract and detect fine details of the earth's surface targets and are not capable of distinguishing targe ts as well. On the other hand, Hyperspectral images such as the Earth Observer-1 (EO-1) can measures the energy in narrower bands compared to multispectral sensors. Hyperspectral sensors have more than 240 contiguous spectral bands, therefore it has sufficient spectral resolution to identify specific surface targets. Hyperspectral imagery also defined as imaging spectroscopy (Miao et al., 2007). Recently, these images are mostly used in the geological survey because it can detect different geological formations and distinguish the alterations in the rock strata, weathering properties, and landforms (Sudharsan et al., 2019; Ting-ting \& Fei, 2012; Yousefi et al., 2016). This allows many of the constraints of satellite imagery to be resolved when mapping ore mineralization zones in high resolution (Zhang \& Pazner, 2007). The research demonstrates digital image processing and SAM-classification on the EO-1 imagery to identify lithological and mineral units at part of Kirkuk anticline in northern Iraq. The results and the applied technique of this study considered very importantly in the practical applications related to the field of primary oil survey, and the relevance of the detected lithology and minerals to the local tectonic setting could provide new insights into the tectonic control on Kirkuk anticline and surrounded area. In addition, the other aim of the study is to understand hyperspectral data processing, and spectral analysis for detecting the areas, which may contain economic minerals, as well as to determine the appropriate processing method to be separated in Eo-1 imagery.

\section{STUDY AREA}

\subsection{Geographical Location}

Area under investigation covers about $\left(120.5 \mathrm{~km}^{2}\right)$ and located in the north of Iraq and follows administratively to the Kirkuk governorate. The study area situated in the northeastern part of Iraq and bounded from the northeast by Zagros Mountains and the western parts of the Lower Zab. While it's bounded from the southeast by the Tigris River, the southern Hamreen Mountains, and the southwestern parts of the Sirwan River (Diyala River), and determined between Latitude $35^{\circ} 0.0^{\prime \prime} \mathrm{N}-35^{\circ} 52^{\prime} 30.0^{\prime \prime} \mathrm{N}$ and Longitude $43^{\circ} 55^{\prime} 30.0^{\prime \prime} \mathrm{E}-44^{\circ} 01^{\prime} 30.0^{\prime \prime}$ E Figure 1.

\subsection{Geological Setting}

The study area is considered to be part of Kirkuk anticline. It is an asymmetrical, cylindrical anticline, with a trend towards North West- East, South East, and a distance of approximately $(125) \mathrm{km}$. It is divided into two prominent saddles into three structural domes: Khurmala, Avanah, and Baba domes (AlSheikhly et al., 2015). 


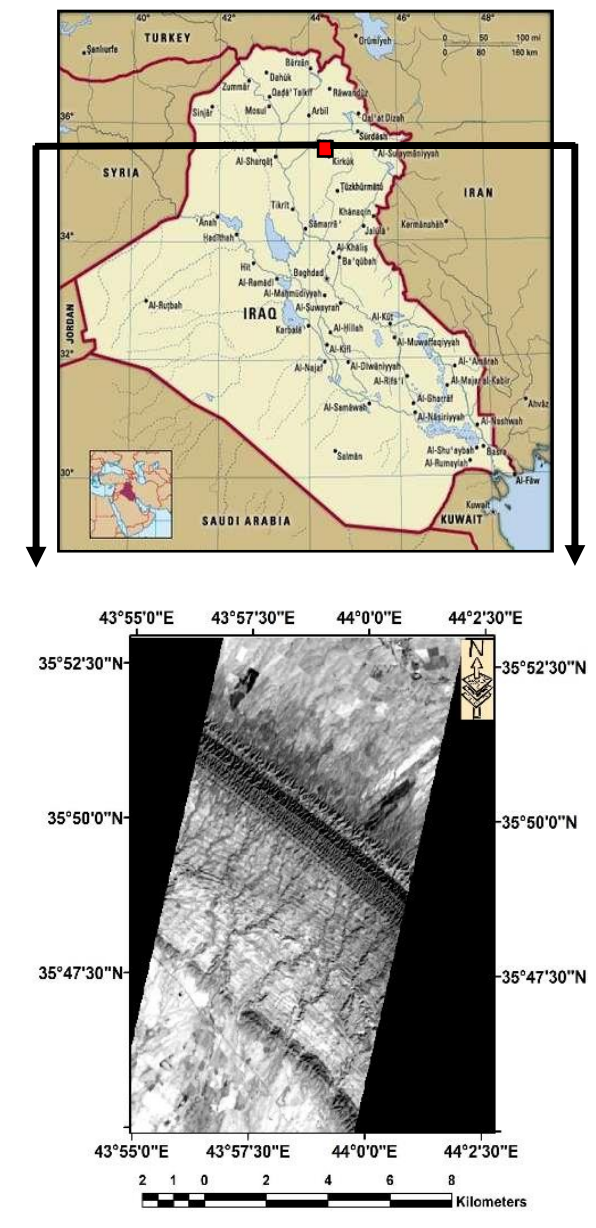

Figure 1. Geographical location of Part of Kirkuk anticline

Tectonically, the area is situated in the Low Folded Zone of Iraq (Al-Kadhimi et al., 1996), which consists of a series of folds with a low amplitude, widely spaced, and gentle, trending NW - SE, and E-W. According to the Iraqi Geological Survey (Sissakian \& Fouad, 1993), stratigraphic units exposed on the anticline in the study area consist of four geological formations from Miocene to quaternary age, Figure 2. Fatha (Middle Miocene) is the oldest formation that exposed at the core of Kirkuk anticline consists of limestone, gypsum, green marl, and claystone. Injana is the second formation, that exposed widely in the study area includes rock units of red and reddish-brown clastic rocks. The third formation is Mukdadiya that contains pebbly sandstone, siltstone, and claystone, while the last exposed formation is Bai Hasan that includes conglomerate, sandstone, and claystone. The Quaternary deposits are well developed in the study area, specifically, polygenetic deposits that fill synclinal troughs areas, with other various types, for example, slope and sheet runoff deposits, residual gravels, valley filling deposits. The area under investigation has a semi-arid climate with an average annual rainfall below $(58 \mathrm{~mm})$ and mean annual temperatures about $\left(20 C^{0}\right)$ (Soran, 2008). The topographical setting of the study area is characterized by gentle to moderate slope terrains with elevations of about (300-370) $\mathrm{m}$.above mean sea level (as measured on the digital elevation model). 


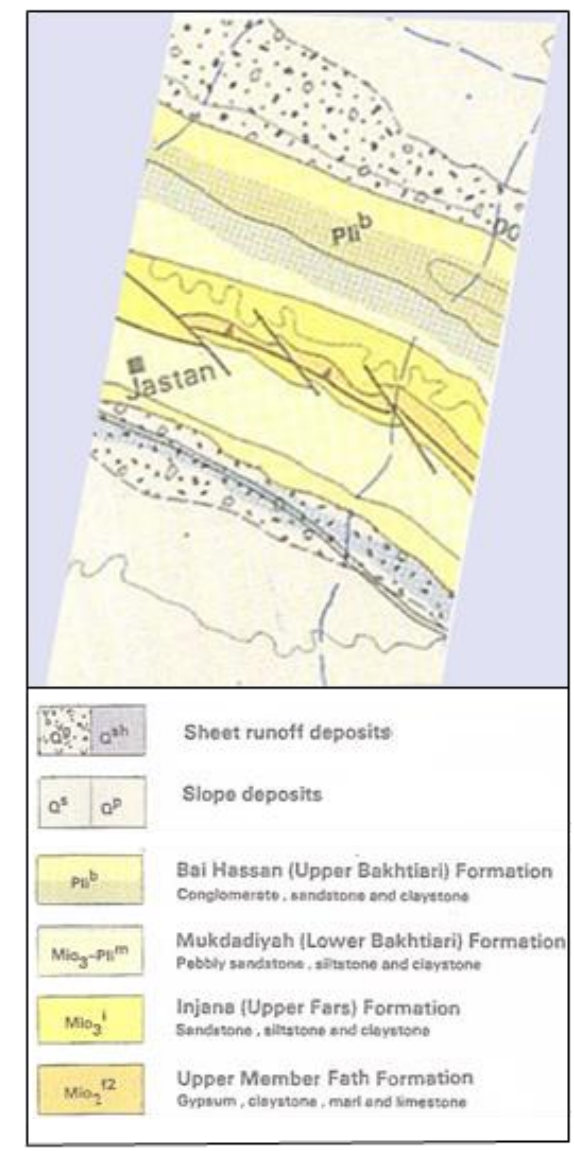

Figure 2. Geological part of Kirkuk anticline (Sissakian \& Fouad, 1993)

\section{DATA USED}

EO-1 Hyperion hyperspectral image (Earth Observation-1) designed by NASA's in (Nov. 2000) (Tiwari et al., 2010; White et al., 2007). According to (Jafari \& Lewis, 2012), the EO-1 satellite follows the same Landsat orbits of about 1 min., and the spatial resolution is about $(30 \mathrm{~m})$ with a standard scene of $42 \mathrm{~km}$ long and $7.7 \mathrm{~km}$ wide. The Hyperion is high spectral resolution imagery. The instrument operates on the push broom. It can be also representative one $(100 \mathrm{~km} \times$ $7.5 \mathrm{~km}$ ) area per image and captures the area's arriving radiation in the zone ranged from $(0.4-2.4 \mu \mathrm{m})$, and then the Hyperion capable to resolve 220 spectral bands in (242 bands of EO-1) with an average half full-width of 10.9 (Farifteh et al., 2013; Pu et al., 2005). The data utilized in this research is a subset of the EO-1 Hyperion image (Row 35/Path 169); dated 3 Nov. 2013. Image processing was done using (ENVI) software as well as (ArcMap) was used for preparing final maps.

\section{PREVIOUS WORKS}

Previous works focused on the geology, tectonic, and geomorphology of Kirkuk anticline, but no previous studies have used the hyperspectral images. Several studies have used Landsat and Aster imagery satellite for detecting the lithological units and rock alteration by applying digital image processing, for example, image transformation i.e. principal component analysis and image ratio, and set of mineralogical and lithological mapping have been created. 
Finally, some of these studies have shown that Kirkuk anticline increasingly affected by hydrocarbon seepage (Perry et al., 2011; Thannoun, 2012; Thannoun et al., 2018). Parts of the Kirkuk anticline studied by (Perry et al., 2011). They compiled the altered outcrops map by applying some of the advanced classifications to the Landsat and Aster imagery. Also, (Thannoun, 2012) studied Avanah dome located within the area under investigation, and conducted three Landsat image processing to detect anomalous areas or alteration zones due to hydrocarbon seepages.

\section{RESEARCH METHODOLOGY}

The classification was done by performing the spectral angular mapper (SAM). The adopted methodology consisting of multiple stages is outlined in Figure. 3:

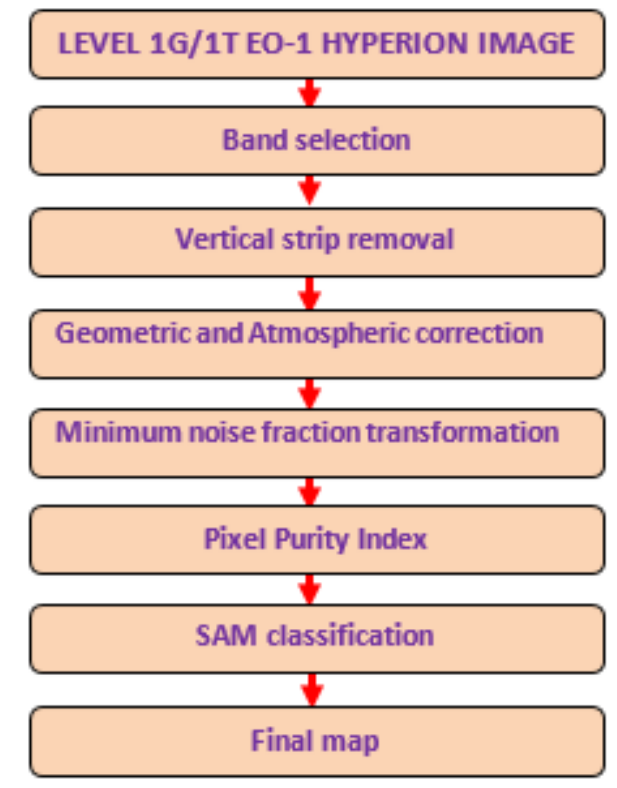

Figure 3. The methodology of the study

\subsection{Pre-processing}

Hyperion level 1G / 1T data includes some noises, so digital processing has to be conducted first (Datt et al., 2003; Farifteh et al., 2013; Goodenough et al., 2003; Staenz et al., 2002). In this research, the EO-1 Hyperion image was prepared and corrected to remove the vertical strip and geometric and atmospheric correction.

\subsubsection{Band selection (removed non- information and absorption bands)}

Multi bands of EO-1 Hyperion images have been removed from the data-set of 242 bands before utilizing the imagery for processing. Some of these bands are not having pixel information called zero bands (Kumar \& Yarrakula, 2017), but contain significant noise, water vapor absorption, and higher vertical stripping. The removed or zeroed bands are set between B1to B7, B58 to B76, and B 221 to $\mathrm{B} 242$. Water vapor regions located in the bands B120 to B132, B165 to B182, and B221 to B224 respectively. Some of these bands consist of systematic noise 
called vertical stripes, which reduce data quality and interpretability. By using visual interpretation, the bands with vertical stripping are recognized and removed manually. These bands are $\mathrm{B} 1$ to B7; B58 to B78; B80 to B82; and B221to B242. The remaining 194 bands have been selected for processing.

\subsubsection{Vertical strip removal}

One of the most challenging troubles with the EO-1 Hyperion was a lot of long- track stripes in some of EO-1bands. Image display vertical striping, which means that pixel brightness varies from that of the nearby pixels, and therefore this noise may negatively influence the classification. The vertical strip could be the outcome of differences in the cross-track direction cells (Mason, 2002). Subset images include 143 selected bands that have been minimized by vertical strip checking for each band, and the digital number value is replaced by the average of the digital number of the neighboring columns. By applying the following equations (Goetz et al., 2003), all the stripes noise in the EO-1 imagery can be processed.

$$
\begin{gathered}
X^{\prime} i j b=(X i j b-\mu j b) \frac{\delta b}{\delta j b}+\mu b \\
X^{\prime} i j b=(X i j b-\mu j b) \frac{\delta m}{\delta j b}+\mu m
\end{gathered}
$$

Where $X i j b$ is the pixel value in column $j$, row $i$, and band $b$. Xijb is related to calculating distortion of pixel value in row $i$, column $j$, and band $b$. Both $\mu b$ and $\sigma b$ is the mean of the standard deviation of band k. $\mu j b$ and $\sigma j b$ is the mean of the standard deviation of column $j$ in band $b$. $\mu \mathrm{m}$ and $\sigma m$, are the mean of the standard deviation.

$$
\begin{aligned}
& \text { The subset image imported by } \\
& \text { using tool import utility } \\
& \text { (Hyperion_tool.sav) which is available on } \\
& \text { the ENVI web site } \\
& \text { (http://www.iitvis.com) and all the images } \\
& \text { were converted to ENVI format. }
\end{aligned}
$$

\subsubsection{Geometric and Atmospheric correction}

The Hyperion EO-1 image was conveyed as a radiometrically calibrated with level $1 \mathrm{G}$ Hyperion data, and the image was registered in the Landsat
ETM+2001 imagery (Path 169, Row 35) using the image to image geometrical correction method. Several points selected as Ground Control Points (GCP) between the test and the reference images. The accuracy of the operation was important and concluded by Root Mean Square (RMS). The value of this factor was 0.7 pixels using 13 GCP. Some of the bands chosen for the post-processing. Such bands are quickly atmospheric through (FLAASH) a model that provides atmospheric correction of hyperspectral imagery in (VNIR to SWIR) and uses the factors of atmospheric compensation directly from the data found within the image scene, in the absence of ancillary information (Pervaiz et al., 2016; Pervez \& Khan, 2015). The following equation explains the FLAASH method for atmospheric correction (Kumar \& Yarrakula, 2017; Magendran \& Sanjeevi, 2013).

$$
L=\left(\frac{A r}{1-r e S}\right)+\left(\frac{B r e}{1-r e S}\right)+L a
$$


This equation detects the absolute reflectance acquired by FLAASH modular. $r$ is the reflectance of the pixel surface, $p e$ is the reflectance surface to the pixel and $\mathrm{S}$ is the atmosphere albedo, the surrounding area, $L a$ atmosphere radiance backscattered. $\mathrm{A}$ and $\mathrm{B}$, are coefficients. Atmospheric correction carried out by using the extension tool (Hyperion tool.sav).

\subsection{Post-processing}

Image post-processing includes:

\subsubsection{Data dimensionality detection}

In this study, the minimum noise fraction transformation (MNF) implemented to the pre-atmospheric correction image to detect the inherent dimensionality of this data and to reduce uncorrelated spatial noise. The MNF transform based on the concept of principal component analysis (often referred to as PCA, or Karhunen-Loeve) (Hirano et al., 2003). By testing the eigenvalues of the MNF processing, it can be noticed that the first MNF spectral bands (1 and 2 ) have the highest values, while the other one has the lowest values. It is possible to show that by using
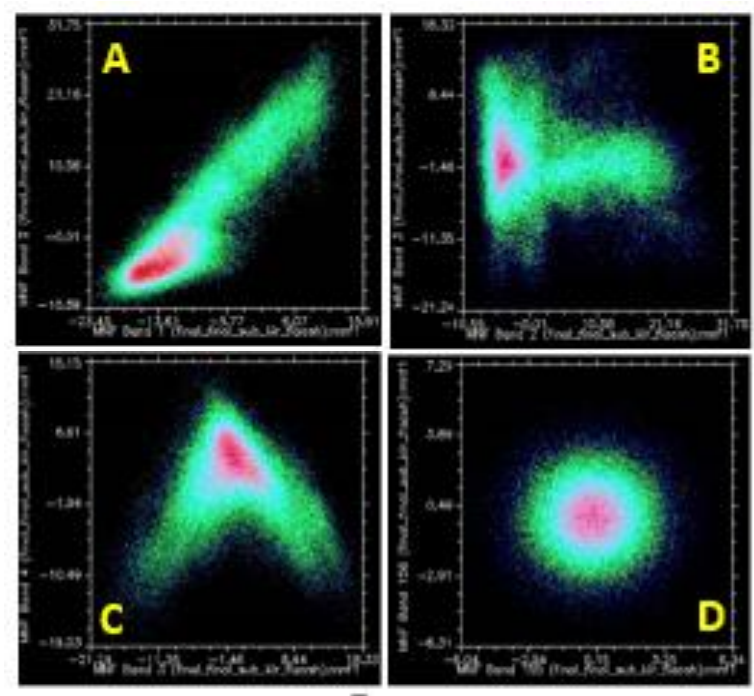

Figure 4. MNF bands scatterplots. (a) band1 $\mathrm{v}$ band2, (b) band $2 \mathrm{v}$ band3, (c) band $3 \mathrm{v}$ band 4 , (d) band $155 \mathrm{v}$ band 156 ) 


\subsubsection{Spectral Angle mapper classification}

This processing is a physical spectral classifier using an n-dimensional angle to match reference spectra pixels (Kruse et al., 1993). The algorithm of this processing based on an optimal assumption that a single pixel of images reflects one certain ground target cover material, and can only be allocated to a one ground cover class. This processing method determines the spectral similarity between the spectra of the pixel by estimating the angle between the spectra (i.e. the pixel spectra or image spectrums or to identified spectra of reference reflectance) and by dealing them as vectors in a feature space. The classification applied to calibrated reflectance data is comparatively insensitive to albedo and illumination impacts (Hassani, 2017). The endmember spectra used in SAM classification can be extracted from ASCII files with the ASD fields spectroradiometer or spectral libraries, as well as, extracted directly from image pixels, as the region of interest average spectra. SAM correlates the angle between the vectors of image pixel and endmember spectrum in the feature space Figure 5., and then the smallest angles are more precisely exemplified to the reference spectrum. Moreover, Pixels far beyond the determined high angle threshold are not classified. SAM detects the spectral similarity by applying the following equation:

$$
\alpha=\cos ^{-1}\left[\frac{\sum_{i=1}^{n} t_{i} r_{i}}{\left[\sum_{i=1}^{n} t_{i}^{2}\right]^{1 / 2}\left[\sum_{i=1}^{n} r_{i}^{2}\right]^{1 / 2}}\right]
$$

Where $\alpha$ is a spectral angle, $t$ is an image pixel spectrum, $r$ is a referee spectrum, and $\mathrm{n}$ is the number of bands available. SAM measures the data points of angular direction and not their magnitude, and is relatively insensitive to albedo effects and illumination (Falcone \& Gomez, 2005). This can be useful for detecting many materials or targets that have very different spectra.

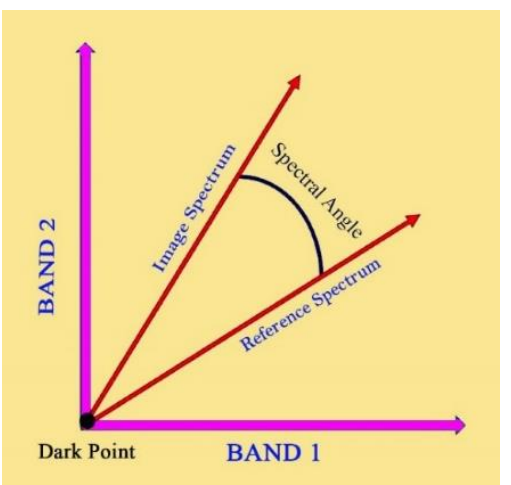

Figure 5. The angle in the feature space between reference spectrum and image

\section{RESULTS AND DISCUSSION}

EO-1 imagery used in this research obtained from part of Kirkuk anticline. The geological structure known as Kirkuk oil fields. Some of the natural 
gas springs and hydrocarbon seepage has been recorded. Therefore, lithological and mineral variations result from rocks and soil alteration caused by gaseous emission from the subsurface reservoir. In mineral and lithological mapping using SAM classification, it is assumed that each class has a single spectral signature and mean spectrum of each sample selected (Crosta et al., 1998; Rowan et al., 2000) that shall be considered as the alternative of the spectral form of the class. Key spectral signatures of earth's materials allow direct detection of vegetation, minerals, rocks, and mapping of hydrothermal alteration minerals, main lithological units, and mineral resources (Mazhari et al., 2017). Endmember selection is the most important step in the SAM-classification. In this classification, three different

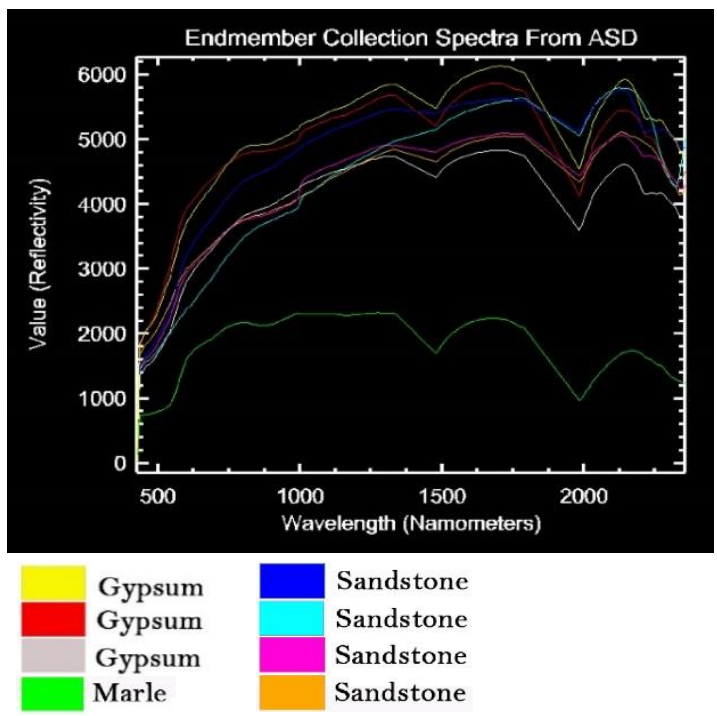

Figure 6. Measured reflectance curves by ASD

In the EO-1 Hyperion image, the SAM classifier measures the digital number of all bands for each pixel and then detects the resemblance between the direction of the image pixel spectral signature i.e., color and the specific class in the spectrometer and USGS digital library spectral. Source three: deriving endmembers from the purest pixels in the Hyperion image which was done by endmembers or spectra sources are used. Source one: is done by Analytical Spectral Devices (ASD) Spectrometer in spectral analysis laboratory (Remote Sensing Center- Mosul University), with a full range of resolution (i. e. $350 \eta \mu$ to 2500 $\eta \mu$ ), and then five samples for the main lithological units were collected and measured by ASD Figure 6. Source two: reference spectra have been taken from the U. S. Geological Survey spectral library for minerals, Figure 7 because, without geochemical analysis, it is difficult to identify different types of altered minerals on the field. Endmembers that provided by each source, generated as the training area for SAM classification.

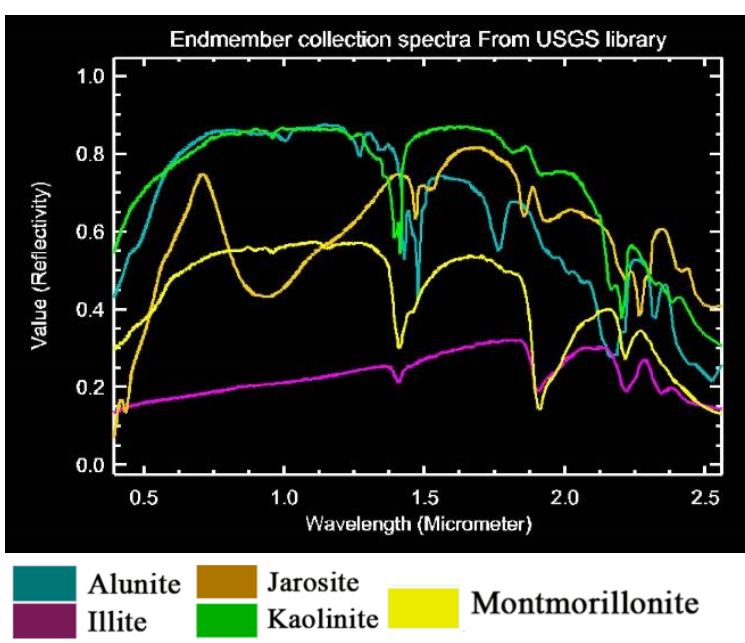

Figure 7. Reflectance curves by USGS spectral library

applying MNF and PPI. The output of the SAM classification is a color-coded image that displays the highest SAM matching for the prevalent content of each pixel. After processing the endmember of (13) minerals through the SAM classification, the result showing a good match at each pixel between Hyperion image spectra and unknown spectra. The general lithological and mineral map generated 
from EO-1 Hyperion data using SAM classification depicted in Figure 8. The classified image reveals the distribution of specific different lithological and mineral types in the area. The location of the main lithological unit in the area under investigating accurately corresponds to the geological map. The upper member of Fatha formation located in the central core of Kirkuk anticline with scattered and small outcrops towards the limbs.

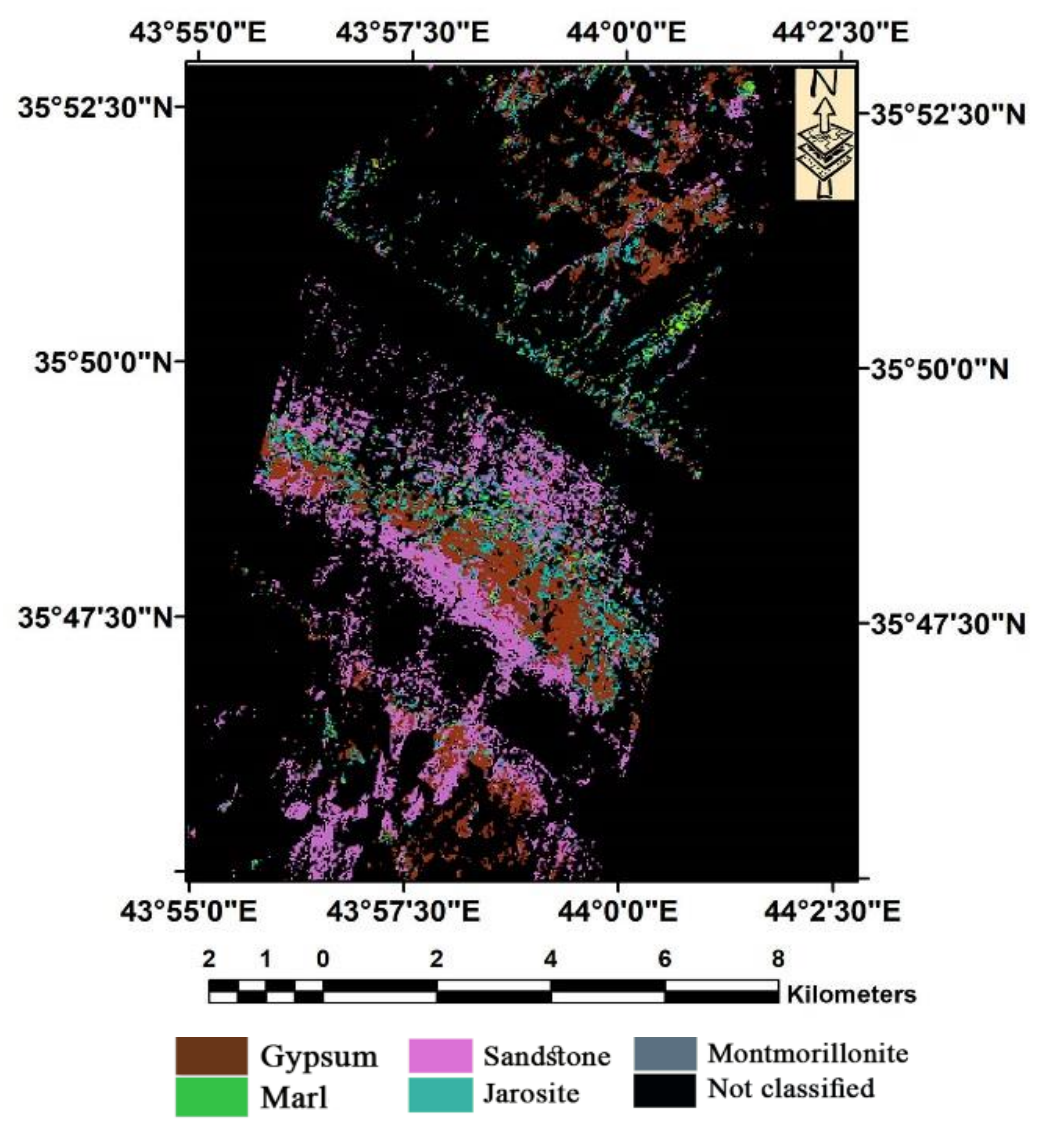

Figure 8. Color-coded image of SAM classification

Gypsum was the most common lithology mapped in the classification, with marl identified in isolated and small clumps. Injana formation was prevailed in the central core towards the limbs and the Sandstone was the most common lithology mapped in the classification. As shown in Figure 8, the lithological units of Bai Hassan and Mukdadiya formations, which commonly consist of conglomerates and pebbly sandstone, were not record in the classification and appeared in black due to the lack of true endmembers available in the area under investigating. Five hydrocarbon seepage- related minerals were selected, they are Alunite, Illite, Jarosite, Kaolinite, and Montmorillonite. The classified Hyperion image shows that these minerals are the most dominant altered minerals, and it can be seen a small amount of Illite mapped in the study area. Some of these minerals agree with the research, by (Perry et al., 2011) in the existence of two types of minerals in Kirkuk anticline as evidence of hydrocarbon seepage occurrence. According to (Perry et al., 2011; Thannoun, 2012) and (Thannoun et al., 2018), the entire area of Kirkuk anticline has been extensively affected by 
hydrocarbon seepage, and many of the gas springs issued from the subsurface reservoir is recorded. Additionally, the SAM rule images help better observation of lithological and mineral units. Rule images measured the distance of actual angular (in radians) of each spectrum in the EO-1 image and of each endmember or spectrum in n-dimensional space with a
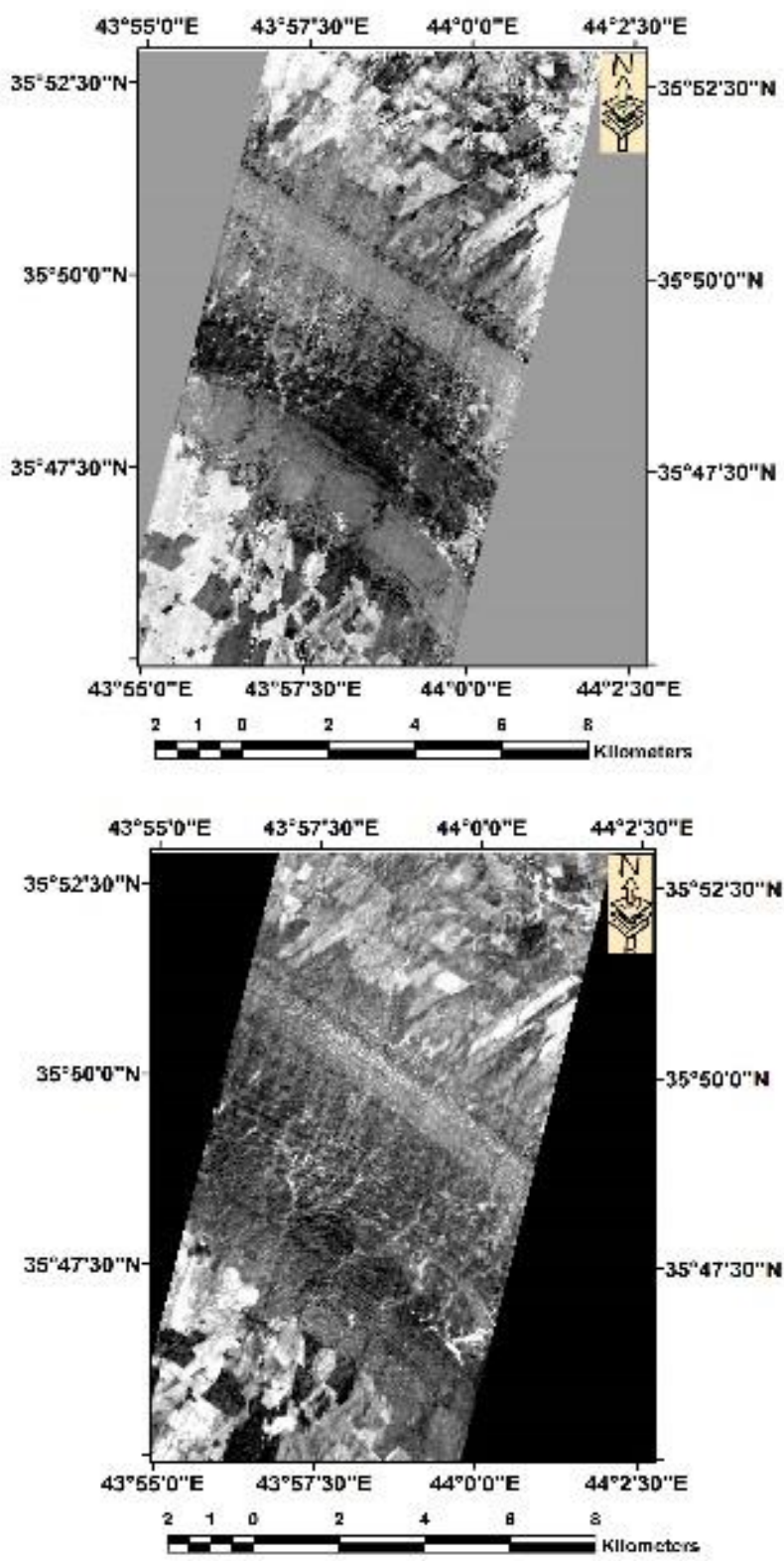

threshold angle equal to (0.3) radians. Figure 9, shows the four rule images produced by the SAM classification using four selected spectra. In the SAM rule image, Grayscale density values indicate the spectral angle values, as well as, the darker locations refer to the reference spectrum closer matches and then show more relevance to the defined class.
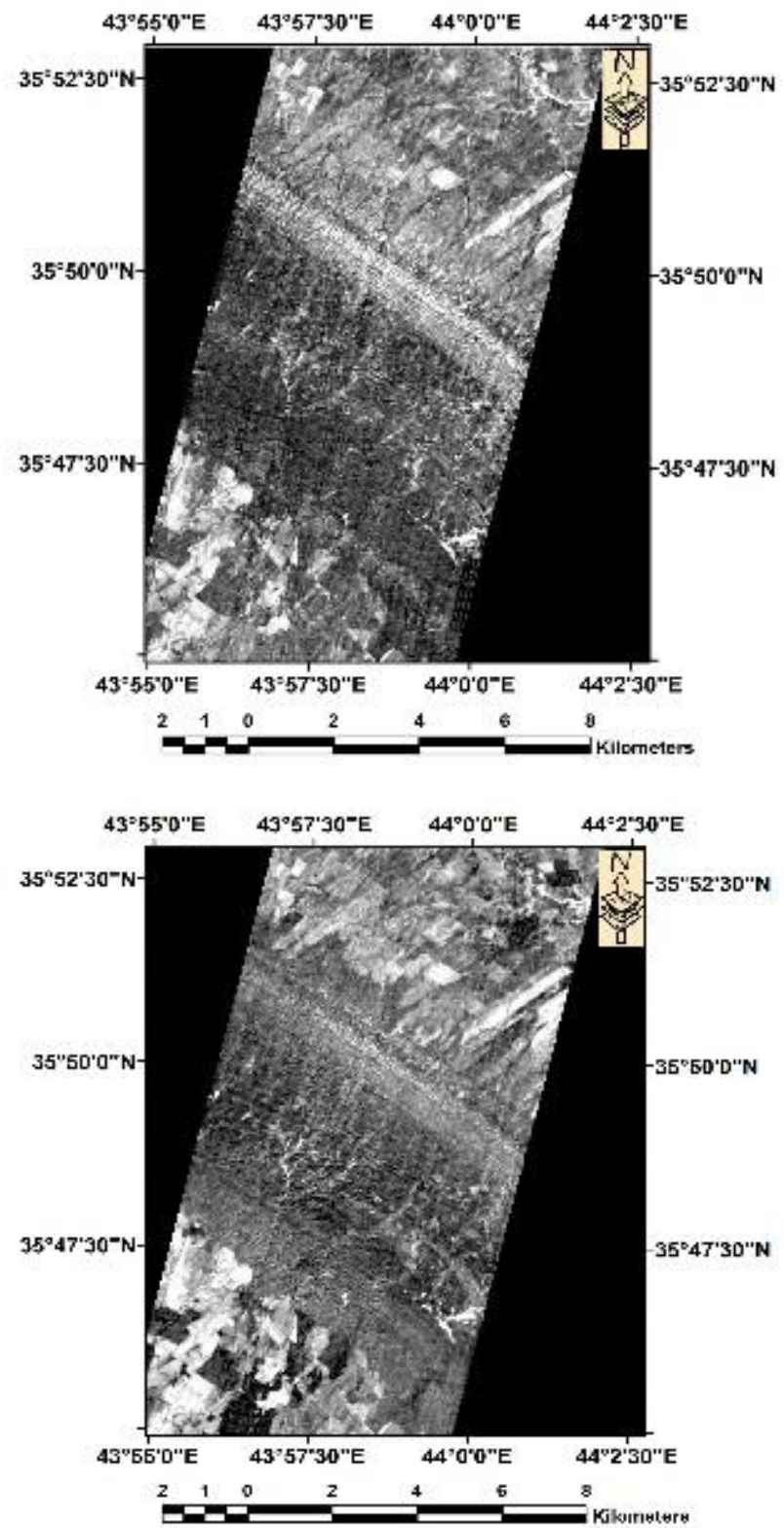

Figure 9. SAM rule images 


\section{CONCLUSIONS}

SAM classification is taken as an example to explain the hyperspectral satellite technology to determine mineralogical and lithological units. The Use of remote sensing in geology, as a form of principal procedures in geological survey, plays an important role in exploring and mineral prospecting. The results proved that the distribution of the mineralogical and lithological units in the outcrops of Kirkuk anticline can be identified by integrating between SAM classification and hyperspectral imagery. SAM classification and endmembers were selected from three different sources, offering an effective identification method for economic minerals. Eo-1 Hyperion imagery can recognize mineral precisely compared with traditional methods for multispectral technology. This study can be developed $\mathrm{d}$ as a good procedure for future studies of ideas related to hyperspectral imagery for mineral exploration in the Low Folded Zone of Iraq.

\section{ACKNOWLEDGMENT}

The author is very grateful to the University of Mosul and Remote Sensing Center for the facilities they have provided.

\section{REFERENCES}

Al-Kadhimi, J. A. M., Sissakian, V. K., Fattah, A. S., \& Deikran, D. B. (1996). Tectonic Map of Iraq, scale 1: 1000 000, 2nd edit. GEOSURV, Baghdad, Iraq, 1-38.

Al-Sheikhly, S. S., Tamar-Agha, M. Y., \& Mahdi, M. M. (2015). Basin analysis of Cretaceous to Tertiary selected wells in Kirkuk and Bai Hassan Oil Fields, Kirkuk, Northern Iraq. Iraqi Journal of Science, 56(1B), 435-443.
Boardman, J. W., Kruse, F. A., \& Green, R. O. (1995). Mapping target signatures via partial unmixing of AVIRIS data.

Crosta, A. P., Sabine, C., \& Taranik, J. V. (1998). Hydrothermal alteration mapping at Bodie, California, using AVIRIS hyperspectral data. Remote Sensing of Environment, 65(3), 309319.

Datt, B., McVicar, T. R., Van Niel, T. G., Jupp, D. L. B., \& Pearlman, J. S. (2003). Preprocessing EO-1 Hyperion hyperspectral data to support the application of agricultural indexes. IEEE Transactions on Geoscience and Remote Sensing, 4l(6), 1246-1259.

Falcone, J. A., \& Gomez, R. (2005). Mapping impervious surface type and sub-pixel abundance using hyperion hyperspectral imagery. Geocarto International, 20(4), 3-10.

Farifteh, J., Nieuwenhuis, W., \& GarcíaMeléndez, E. (2013). Mapping spatial variations of iron oxide byproduct minerals from EO-1 Hyperion. International Journal of Remote Sensing, 34(2), 682-699.

Goetz, A. F. H., Kindel, B. C., Ferri, M., \& Qu, Z. (2003). HATCH: Results from simulated radiances, AVIRIS and Hyperion. IEEE Transactions on Geoscience and Remote Sensing, 41(6), 1215-1222.

Goodenough, D. G., Dyk, A., Niemann, K. O., Pearlman, J. S., Chen, H., Han, T., Murdoch, M., \& West, C. (2003). Processing Hyperion and ALI for forest classification. IEEE Transactions on Geoscience and Remote Sensing, 41(6), 1321-1331.

Hassani, K. (2017). Multispectral and Hyperspectral Remote Sensing of Quaternary Sediments in Tule and Snake Valleys, Lake Bonneville, Utah. Ohio University.

Hirano, A., Madden, M., \& Welch, R. (2003). Hyperspectral image data for 
mapping wetland vegetation. Wetlands, 23(2), 436-448.

jaber Nasir, S. (2018). Review of the Role of Remote Sensing Applications in Mineral Exploration and Sustainable Development in Oman. International Journal of Environment and Sustainability, 6(3).

Jafari, R., \& Lewis, M. M. (2012). Arid land characterisation with EO-1 Hyperion hyperspectral data. International Journal of Applied Earth Observation and Geoinformation, 19, 298-307.

Kruse, F. A., Lefkoff, A. B., Boardman, J. W., Heidebrecht, K. B., Shapiro, A. T., Barloon, P. J., \& Goetz, A. F. H. (1993). The spectral image processing system (SIPS)-interactive visualization and analysis of imaging spectrometer data. AIP Conference Proceedings, 283(1), 192-201.

Kumar, M. V., \& Yarrakula, K. (2017). Comparison of efficient techniques of hyper-spectral image preprocessing for mineralogy and vegetation studies.

Magendran, T., \& Sanjeevi, S. (2013). A study on the potential of satellite image-derived hyperspectral signatures to assess the grades of iron ore deposits. Journal of the Geological Society of India, 82(3), 227-235.

Mason, P. (2002). MMTG A-List Hyperspectral Data Processing Software. 920C. CSIRO, Division of Exploration and Mining, Sydney, Australia.

Mazhari, N., Shafaroudi, A. M., \& Ghaderi, M. (2017). Detecting and mapping different types of iron mineralization in Sangan mining region, NE Iran, using satellite image and airborne geophysical data. Geosciences Journal, 21(1), 137148.
Melesse, A. M., Weng, Q., Thenkabail, P. S., \& Senay, G. B. (2007). Remote sensing sensors and applications in environmental resources mapping and modelling. Sensors, 7(12), 32093241.

Miao, X., Gong, P., Pu, R., Carruthers, R. I., \& Heaton, J. S. (2007). Applying class-based feature extraction approaches for supervised classification of hyperspectral imagery. Canadian Journal of Remote Sensing, 33(3), 162-175.

Perry, S. L., Kruse, F. A., \& Carlston, C. (2011). Evidence of Hydrocarbon Seepage Using Multispectral Satellite Imagery, Kurdistan, Iraq. 73rd EAGE Conference and Exhibition-Workshops 2011, cp-239.

Pervaiz, W., Uddin, V., Khan, S. A., \& Khan, J. A. (2016). Satellite-based land use mapping: comparative analysis of Landsat-8, Advanced

Land Imager, and big data Hyperion imagery. Journal of Applied Remote Sensing, 10(2), 26004.

Pervez, W., \& Khan, S. A. (2015). Hyperspectral hyperion imagery analysis and its application using spectral analysis. The International Archives of Photogrammetry, Remote Sensing and Spatial Information Sciences, 40(3), 169.

$\mathrm{Pu}, \mathrm{R} ., \mathrm{Yu}, \mathrm{Q}$., Gong, P., \& Biging, G. S. (2005). EO-1 Hyperion, ALI and Landsat 7 ETM+ data comparison for estimating forest crown closure and leaf area index. International Journal of Remote Sensing, 26(3), 457-474.

Rowan, L. C., Crowley, J. K., Schmidt, R. G., Ager, C. M., \& Mars, J. C. (2000). Mapping hydrothermally altered rocks by analyzing hyperspectral image (AVIRIS) data of forested areas in the Southeastern 
United States. Journal of Geochemical Exploration, 68(3), 145-166.

Saibi, H., Bersi, M., Mia, M. B., Saadi, N. M., Al Bloushi, K. M. S., \& Avakian, R. W. (2018). Applications of Remote Sensing in Geoscience. Recent Advances and Applications in Remote Sensing, 181.

Sissakian, V. K., \& Fouad, S. F. (1993). Geological Map of Kirkuk Quadrangle. Sheet NI-38-2, scale 1: 250000, GEOSURV, Baghdad, Iraq.

Soran, N. S. (2008). Hydrogeochemical properties of groundwater in the vicinity of Al-Hawija plain-Kirkuk, Iraq. Journal of Kirkuk UniversityScientific Studies, 3(2), 2008.

Staenz, K., Neville, R. A., Clavette, S., Landry, R., White, H. P., \& Hitchcock, R. (2002). Retrieval of surface reflectance from Hyperion radiance data. IEEE International Geoscience and Remote Sensing Symposium, 3, 1419-1421.

Sudharsan, S., Hemalatha, R., \& Radha, S. (2019). A Survey on Hyperspectral Imaging for Mineral Exploration using Machine Learning Algorithms. 2019 International Conference on Wireless Communications Signal Processing and Networking (WiSPNET), 206212.

Thannoun, R. (2012). Structural control evaluation of hydrocarbon seepages in Northern Iraq using remote sensing techniques. Unpublished Ph. D. Thesis, College of Science, Geology Dept. Mosul University.

Thannoun, R., Ali, S., \& Al-munaem, N. (2018). Geobotanical Study of Some
Areas South-Western Mosul by using Remote Sensing and ASD Datasete. Iraqi National Journal of Earth Sciences, 18(1), 9-26.

Ting-ting, Z., \& Fei, L. (2012). Application of hyperspectral remote sensing in mineral identification and mapping. Proceedings of 2012 2nd International Conference on Computer Science and Network Technology, 103-106.

Tiwari, P. S., Pande, H., \& Aye, M. N. (2010). Exploiting IKONOS and Hyperion data fusion for automated road extraction. Geocarto International, 25(2), 123-131.

White, J. C., Coops, N. C., Hilker, T., Wulder, M. A., \& Carroll, A. L. (2007). Detecting mountain pine beetle red attack damage with EO-1 Hyperion moisture indices. International Journal of Remote Sensing, 28(10), 2111-2121.

Yousefi, B., Sojasi, S., Castanedo, C. I., Beaudoin, G., Huot, F., Maldague, X. P. V, Chamberland, M., \& Lalonde, E. (2016). Mineral identification in hyperspectral imaging using Sparse-PCA. Thermosense: Thermal Infrared Applications XXXVIII, 9861, 986118.

Zhang, X., \& Pazner, M. (2007). Comparison of lithologic mapping with ASTER, hyperion, and ETM data in the southeastern Chocolate Mountains, USA. Photogrammetric Engineering \& Remote Sensing, 73(5), 555-561. 